\title{
Peningkatan Kapasitas Masyarakat Kawasan Wisata Goa Pawon
}

\author{
Vyana Lohjiwa*1, Riadi Darwis ${ }^{2}$, Endah Trihayuningtyas ${ }^{3}$, Tatang Sophian ${ }^{4}$, \\ Renalmon Hutahaean ${ }^{5}$
}

Sekolah Tinggi Pariwisata Bandung, Indonesia $1,2,3,4,5$

Email: vyl@stp-bandung.ac.id

\begin{abstract}
Goa Pawon is one of tourist destination that has begun to be known by West Java's people. In Goa Pawon, there are local people which becomes "ojeg"/motorcycle taxi drivers who often take tourists to Goa Pawon, but the survey results shown that they have not optimized their capacity to be able to act as a frontliner services for tourism. In fact, if they have basic knowledge of tourism and how to serve tourists excellently, tourists will feel satisfied whose impact is to increase their income as well as become agents that can accelerate the promotion and popularity of Goa Pawon.
\end{abstract}

Keywords: Community Capacity; Goa Pawon; Tourism Area.

\begin{abstract}
Abstrak
Kawasan wisata Gua Pawon merupakan destinasi wisata yang sudah mulai dikenal oleh masyarakat Jawa Barat. Pada kawasan wisata ini terdapat masyarakat lokal yang membuka usaha sebagai tukang ojek yang sering mengantar para wisatawan ke lokasi Gua Pawon, namun dari hasil survey yang dilakukan, mereka belum mengoptimalkan kapasitas dirinya untuk bisa berperan sebagai motor penggerak pariwisata. Padahal, apabila mereka memiliki pengetahuan tentang pengetahuan sadar wisata dan melayani wisatawan secara prima, wisatawan akan merasa puas yang dampaknya adalah menambah penghasilan mereka sekaligus menjadi agen yang bisa mempercepat promosi dan popularitas dari Goa Pawon.
\end{abstract}

Kata Kunci: Kapasitas Masyarakat, Goa Pawon, Kawasan Wisata

\section{A. PENDAHULUAN}

Gua Pawon adalah salah satu situs prasejarah yang ada di kawasan Padalarang. Kawasan ini memiliki potensi yang sangat besar untuk dikembangkan menjadi alternatif kawasan wisata budaya dan sejarah setelah ditemukannya kerangka manusia purba yang usianya lebih tua dari yang pernah ditemukan. Kondisinya saat ini memang sangat kontras dengan aktivitas penambangan masyarakat. Saat ini, Pemerintah Kabupaten Bandung Barat dan Provinsi Jawa Barat sudah menjadikan kawasan ini sebagai daerah yang diberikan perlindungan dan pengalihan sebagai kawasan konservasi budaya dan alam. Tahun 2017, Pemerintah Kabupaten Bandung Barat telah melakukan kajian untuk kawasan tersebut sebagai kawasan wisata budaya dan sejarah.

Saat ini tren tingkat kunjungan wisatawan ke kawasan Gua Pawon terus meningkat sejalan dengan hasil temuan dan pemberitaannya di berbagai media massa. Untuk mengantisipasi laju kunjungan wisatawan, sudah sepatutnya masyarakat mempersiapkan berbagai infrasruktur yang memadai, kesiapan tenaga pengelola yang profesional dengan melibatkan unsur masyarakat, fasilitas dan amenitas, hingga faktor pendukung lainnya seperti keterlibatan masyarakat dalam pembangunan pariwisata di Gua Pawon.

Berdasarkan hasil observasi awal dan wawancara dengan para tokoh lembaga swadaya masyarakat setempat, secara umum ditemukan sejumlah fakta antara lain: (1) Sebagian besar masyarakat masih berkutat di usaha penambangan; (2) Sebagian besar masyarakat bekerja di bidang jasa 
transportasi/ojeg; (3) Para pengojeg belum memiliki jiwa sadar wisata sehingga tidak mampu melayani wisatawan dengan prima; dan (4) Para wisatawan belum merasakan adanya sambutan yang ramah dan mengesankan agar mereka bisa lama bertahan dan mempromosikan ulang kepada orang-orang terdekatnya. Berdasarkan fakta-fakta tersebut akhirnya, tim Pengabdian kepada Masyarakat (PkM) tergerak untuk melakukan kegiatan yang bisa meningkatkan gairah keterlibatan masyarakat untuk turut berpatisipasi aktif dengan memiliki sikap sadar wisata sehingga sikap tersebut bisa diaplikasikan untuk dapat melayani wisatawan secara prima, sehingga tujuan kegiatan PkM akan menitik beratkan kepada pemberdayaan masyarakat lokal yang ada di kawasan wisata Goa Pawon agar memiliki sikap sadar wisata dan melatih para pengojek dan pokdarwis di kawasan tersebut untuk dapat melayani wisatawan secara prima.

Saat ini, di Kawasan Wisata Goa Pawon telah memiliki komunitas yang peduli dengan isu lingkungan di daerah tersebut dan aktivitas pengembangan pariwisata yaitu Pokdarwis Gua Pawon yang menangani seluruh pengelolaan kawasan termasuk penataan tukang ojeg sebagai salah satu Frontliner services dalam kegiatan pariwisata. Pokdarwis dan Kelompok Pengojek Goa Pawon yang menjadi mitra dalam melakukan kegiatan PkM. Tim telah menginventaris sebanyak 25 orang yang akan diberikan pelatihan sadar wisata dan pelayanan prima. Pada umumnya, anggota Pokdarwis dan Pengojek Gua Pawon berpendidikan menengah ke bawah. Oleh karenanya pelu berbagai pendekatan yang bisa dikemas menjadi pelatihan yang sifatnya berupa terapan dan praktik nyata.

\section{B. METODE PENGABDIAN}

Metode pada kegiatan PkM ini akan diawali dengan melakukan peninjauan langsung ke lokasi dan melakukan wawancara kepada perwakilan masing-masing kelompok masyarakat, hal ini dimaksudkan agar program kegiatan menjadi lebih tepat guna melihat masalah apa yang dimiliki masyarakat lokal. Selain itu, pengobservasian secara langsung dapat memotret permasalahan menjadi lebih personal, sehingga akan lebih mudah mencari metode yang tepat dalam menyampaikan materi pelatihan. Pelatihan yang dilakukan mencakup: (1) Pelatihan Pengetahuan Sadar Wisata; (2) Pelatihan Pelayanan Prima.

\section{HASIL DAN ANALISIS}

Setelah melakukan kegiatan PkM sesuai dengan metode yang telah dipaparkan, PkM ini bersifat problem-solved sehingga tim PkM memberikan data berupa tanggapan yang diperoleh dari masyarakat dan hasil dari pelatihan yang akan dijelaskan sebagai berikut:

\section{Pelatihan Pengetahuan Sadar Wisata}

Hari pertama kami bertemu dengan Ketua Pokdarwis Goa Pawon, terdapat beberapa fenomena dan permasalahn yang diungkapkan antara lain:

Table 1 Hasil tanggapan dan Pelatihan Pengetahuan Sadar Wisata

\begin{tabular}{lll}
\hline \multicolumn{1}{c}{ TANGGAPAN DARI MASYARAKAT } & \multicolumn{1}{c}{ HASIL PELATIHAN } \\
\hline - $\begin{array}{l}\text { Pada tahun 2012 - 2017 pengelolaan Goa Pawon } \\
\text { dan Stone Garden dilakukan oleh Pokdarwis Goa }\end{array}$ & $\begin{array}{l}\text { Pengabdian kedepannya tetap dilaksanakan di } \\
\text { Goa pawon dengan topik Pemanfaatan Homestay } \\
\text { Pawon; }\end{array}$ & $\begin{array}{l}\text { sebagai salah satu fasilitas di Goa Pawon, } \\
\text { pengelolaan kawasan wisata di Goa Pawon } \\
\text { Pada bulan terakhir di tahun 2017, Stone Garden }\end{array}$ \\
$\begin{array}{l}\text { berinisiatif untuk membentuk Pokdarwis Stone } \\
\text { Garden, sehingga pengelolaan Goa Pawon \& Stone }\end{array}$ & $\begin{array}{l}\text { Pengembangan wisata agro sebaiknya didampingi } \\
\text { Garden dipisah; }\end{array}$ \\
& $\begin{array}{l}\text { oleh mahasiswa IPB, karena kondisi fisik di Goa } \\
\text { Pawon yang berada di kawasan gunung kapur }\end{array}$ \\
\hline
\end{tabular}


- Kondisi ini berpengaruh terhadap tingkat kunjungan ke Goa Pawon yang menurun, dikarenakan wisatawan lebih memilih ke Stone Garden dibandingkan dengan Goa Pawon karena Stone Garden merupakan Daya Tarik Wisata yang baru berkembang (Dibuka pada tahun 2015)

- Kondisi ini juga berpengaruh kepada Pokdarwis dan Komunitas Pengojeg Goa Pawon, yang biasanya di hari libur melayani wisatawan, saat ini menjadi sepi sehingga semangat dari Pokdarwis dan Pengojeg menjadi turun.

- Menanggapi hal ini, Ketua Pokdarwis memberikan ide lain yaitu dengan membuat atraksi baru yang lebih menarik sesuai dengan potensi di sekitar Goa Pawon yaitu Wisata agro.

- Dengan hadirnya wisata agro di Goa Pawon diharapkan dapat menjadi magnet baru untuk wisatawan berkunjung ke Goa pawon dan sekitarnya.

- Kaitan dengan program pengabdian masyarakat adalah dengan pengembangan wisata baru di Goa Pawon, dapat memunculkan semangat baru bagi Pokdarwis dan Para Pengojeg.

- Semangat baru ditunjukkan dengan pelatihan sadar wisata dan pelayanan prima, sehingga pada saat wisatawan berkunjung secara individu maupun kelompok, setiap perangkat masyarakat paham mengenai cara melayani wisatawan secara prima. sehingga membutuhkan treatment lebih untuk menghindari adanya kekeringan di sekitar kawasan.

\section{Sumber: Tim PkM, 2019}

Berikut merupakan dokumentasi kegiatan PkM Pelatihan Pengetahuan Sadar Wisata:
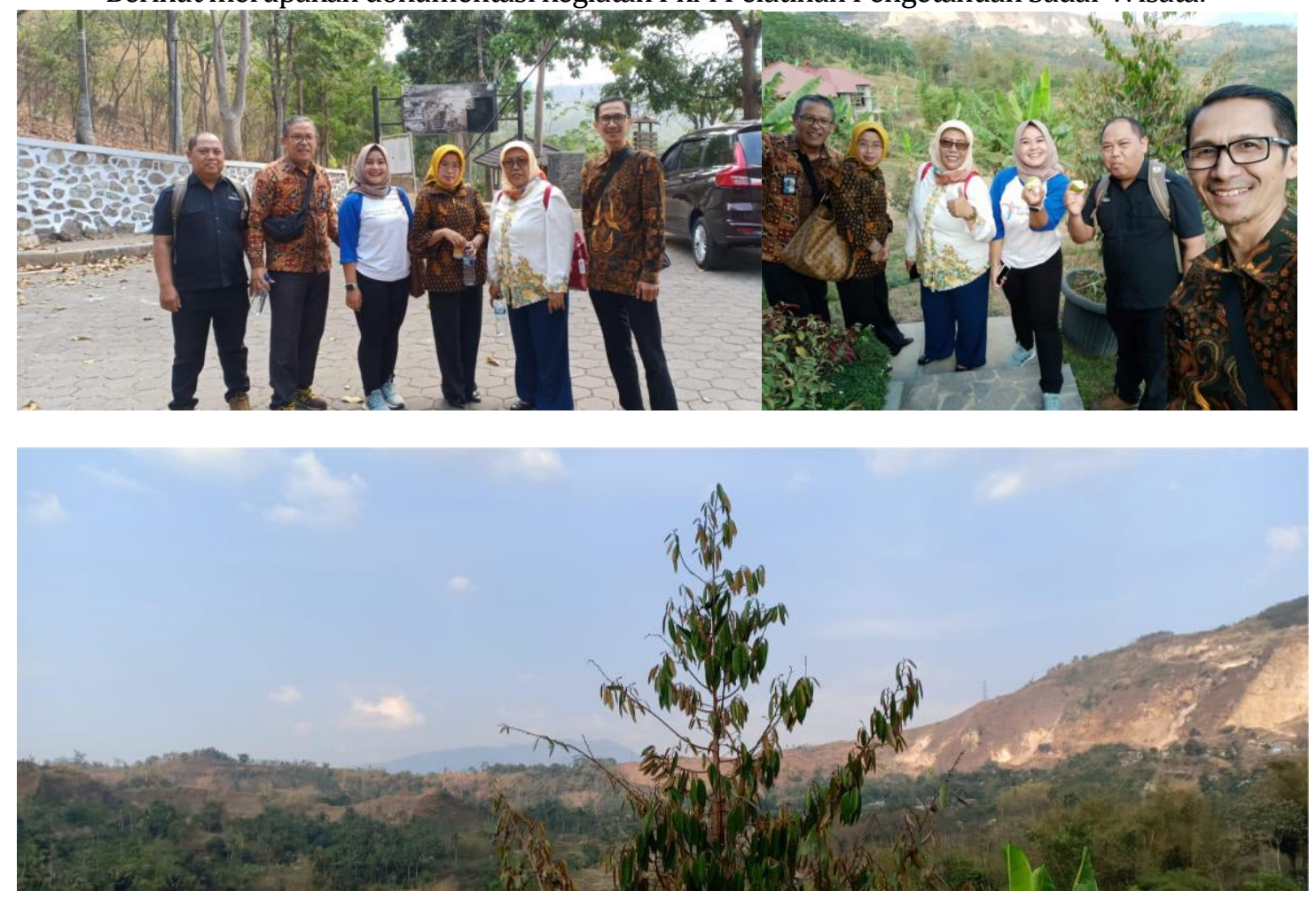


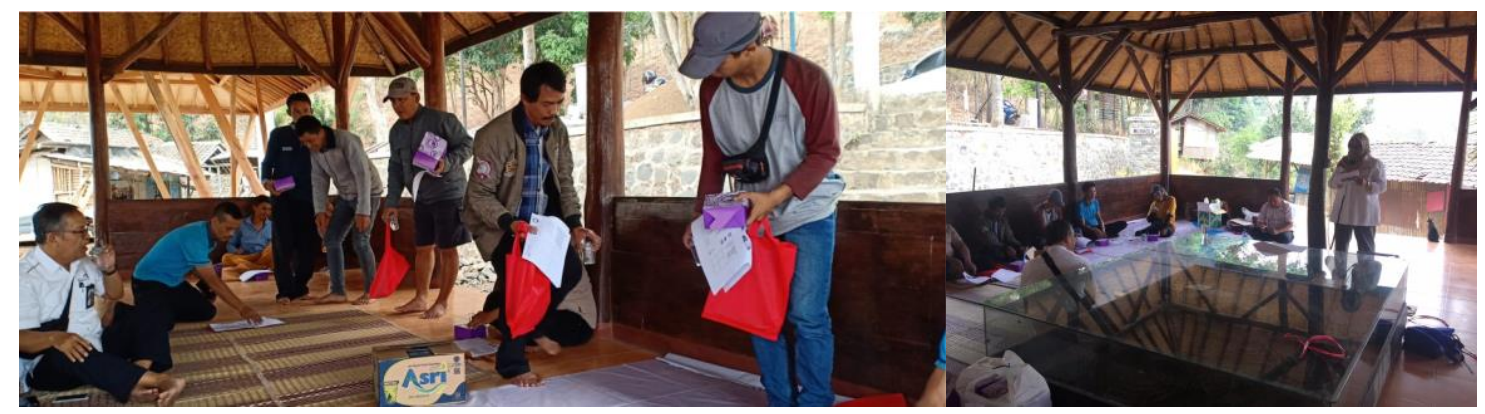

\section{Gambar 1 Dokumentasi PkM Pelatihan Pengetahuan Sadar Wisata}

\section{Sumber: Tim PkM, 2019}

\section{Pelatihan Pelayanan Prima}

Hari kedua bertemu dengan seluruh anggota Pokdarwis dan Komunitas Ojeg Goa Pawon, terdapat beberapa fenomena dan permasalahan yang diungkapkan antara lain:

\section{Table 2 Tanggapan dan Pelatihan Pelayanan Prima}

\section{TANGGAPAN DARI MASYARAKAT}

- Masyarakat menginginkan terdapat satu pengelolaan antara Stone Garden dan Goa Pawon, sehingga pengelolaan yang diciptakan bisa menjadi peluang untuk satu sama lain dalam mengembangkan potensi-potensi wisata baru;

- Masyarakat sudah mulai membuat rumahnya menjadi homestay, masyarakat menginginkan adanya pelatihan untuk SOP homestay.

\section{HASIL PELATIHAN}

- $\quad$ Pokdarwis dan pengojeg memberikan apresiasi yang baik terhadap kegiatan pelatihan, karena selama ini para pengojeg khususnya tidak tau cara melayani wisatawan, bahkan para pengojeg belum paham dengan arti sapta pesona dan penerapannya. Harapan kedepannya adalah melakukan penelitian yang bersifat kontinyu dan berkelanjutan;

- Para pengojeg sepakat pada hari libur akan menggunakan seragam/baju daerah untuk meningkatkan awareness bagi wisatawan yang datang ke Goa Pawon;

- Masyarakat berharap agar Goa pawon bisa menerapkan satu pengelolaan yang terintegrasi dan bersinergi antara seluruh stakeholder.

\section{Sumber: Tim PkM, 2019}

Berikut merupakan dokumentasi kegiatan PkM Pelatihan Pelayanan Prima: 


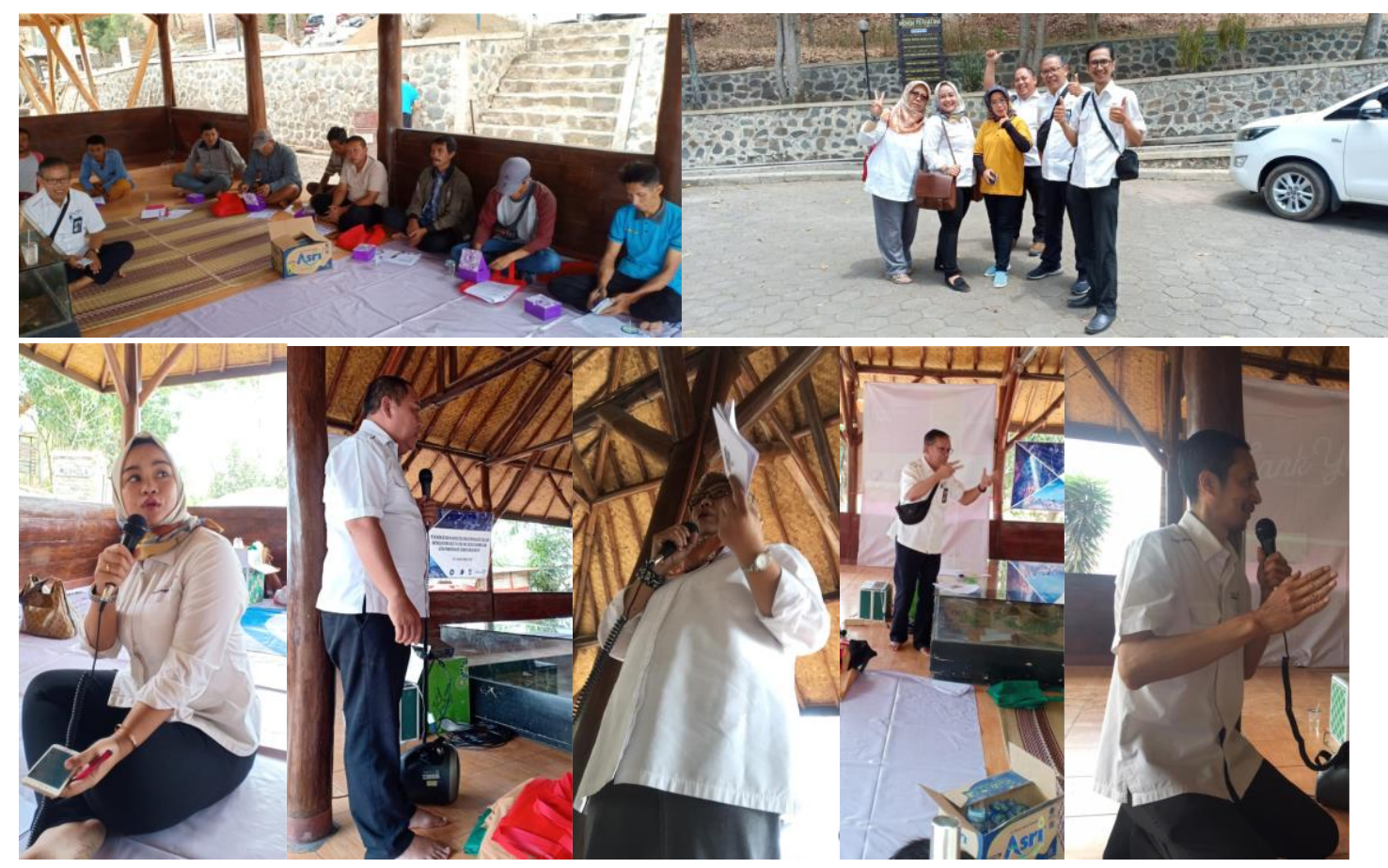

\section{Gambar 2 Dokumentasi Pelatihan Pelayanan Prima}

\section{Sumber: Tim PkM, 2019}

Setelah kegiatan pengabdian kepada masyarakat selesai, terdapat beberapa rujukan unutk kegiatan pemberdayaan kedepannya dengan model berikut:
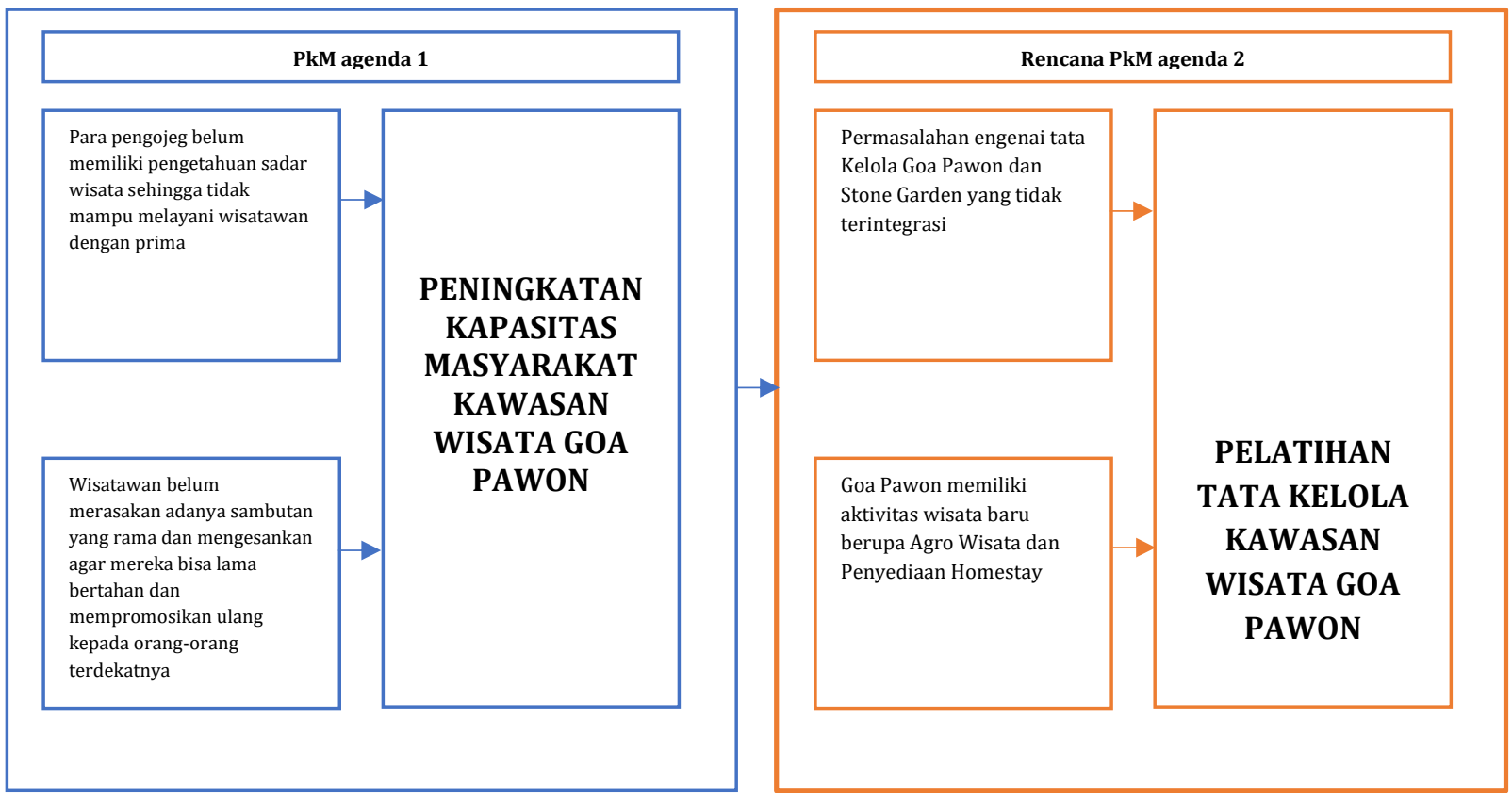

\section{Gambar 3 Model PkM Goa Pawon}




\section{SIMPULAN/CONCLUSION}

Kesimpulan dari program Pengabdian Kepada Masyarakat adalah sebagai berikut:

Peran serta Pokdarwis dan Komunitas pengojeg sudah cukup baik ditandai dengan tingkat kehadiran pelatihan yang sesuai dengan target. Goa Pawon memiliki atraksi baru yaitu Wisata agro, dengan hadirnya wisata agro di Goa Pawon diharapkan dapat menjadi magnet baru untuk wisatawan berkunjung ke Goa pawon dan sekitarnya dan dapat memunculkan semangat baru bagi Pokdarwis dan Para Pengojeg. Semangat baru ditunjukkan dengan pelatihan sadar wisata dan pelayanan prima, sehingga pada saat wisatawan berkunjung secara individu maupun kelompok, setiap perangkat masyarakat paham mengenai cara melayani wisatawan secara prima. Pokdarwis dan pengojeg memberikan apresiasi yang baik terhadap kegiatan pelatihan, karena selama ini para pengojeg khususnya tidak tau cara melayani wisatawan, bahkan para pengijeg belum paham dengan arti sapta pesona dan penerapannya. Harapan kedepannya adalah melakukan penelitian yang bersifat kontonyu dan berkelanjutan. Para pengojeg sepakat pada hari libur akan menggunakan seragam/baju daerah untuk meningkatkan awareness bagi wisatawan yang datang ke Goa Pawon. Masyarakat berharap agar Goa pawon bisa menerapkan satu pengelolaan yang terintegrasi dan bersinergi antara seluruh stakeholder.

Saran dari program Pengabdian Kepada Masyarakat adalah pengabdian kedepannya tetap dilaksanakan di Goa pawon dengan topik Pemanfaatan Homestay sebagai salah satu fasilitas di Goa Pawon, pengelolaan kawasan wisata di Goa Pawon dengan penambahan atraksi Agro Wisata. Pengembangan wisata agro sebaiknya didampingi oleh mahasiswa IPB, karena kondisi fisik di Goa Pawon yang berada di kawasan gunung kapur sehingga membutuhkan treatment lebih untuk menghindari adanya kekeringan di sekitar kawasan. Masyarakat menginginkan terdapat satu pengelolaan antara Stone Garden dan Goa Pawon, sehingga pengelolaan yang diciptakan bisa menjadi peluang untuk satu sama lain dalam mengembangkan potensi-potensi wisata baru. Masyarakat sudah mulai membuat rumahnya menjadi homestay, masyarakat menginginkan adanya pelatihan untuk SOP homestay.

\section{Daftar Referensi}

\section{WEBTOGRAFI}

https://www.mongabay.co.id/2018/12/19/goa-pawon-rumah-manusia-purba-yang-terancamtambang-kapur/

https://jabarprov.go.id/index.php/potensi daerah/detail/158

https://ayobandung.com/read/2021/03/24/204654/mengunjungi-situs-arkeologi-gua-pawon

https://wisato.id/wisata-alam/goa-pawon-sejarah-manusia-purba-sunda-ada-disini/

https://sains.kompas.com/read/2018/12/01/200500123/ahli-ungkap-makanan-manusia-bandungpurba-yang-tinggal-di-goa-pawon

\section{YOUTUBE LINK}

https://www.youtube.com/watch?v=Fafa1r12504 - Liburan ke Wisata Alam Goa Pawon

https://www.youtube.com/watch?v=MB0sPrhWW3I - Exploring Secret Of Bandung | Stone Garden x Goa Pawon

https://www.youtube.com/watch?v=H07YncTGVCY - Ditemukan Fosil Manusia Purba di Goa Pawon | Konon Katanya | Eps 26 | (3/3)

\section{PAPARAN MATERI}

Modul Peningkatan Kapasitas Masyarakat Kawasan Wisata Goa Pawon.

Modul Pelayanan Prima Bagi Host dan Guest. 